\title{
Clinicopathologic significance of mismatch repair protein expression in endometrial cancer
}

\author{
Mi-Kyung Kim, Seung Cheol Kim. \\ Department of Obstetrics and Gynecology, College of Medicine, Ewha Womans University
}

\begin{abstract}
Objective
To evaluate the mismatch repair (MMR) protein expression in endometrial cancer and to assess their association with clinicopathologic outcomes.
\end{abstract}

\section{Methods}

A retrospective review of the clinico-pathologic data and clinical outcomes was performed on patients who were treated for endometrial cancer at a single center between 2014 and 2018. For the study analysis, patients with results for MMR protein immunohistochemistry were included. MMR-deficient (MMR-d) was defined as absence of expression in any of the $4 \mathrm{MMR}$ proteins (MLH1, MSH2, MSH6, and PMS2). Clinical and pathologic outcomes were compared according to the MMR status.

\section{Results}

A total of 146 endometrial cancer patients with available MMR expression data were included. Of these, 41 patients $(28.1 \%)$ showed absence of MMR protein expression (MMR-d). Compared with MMR-proficient (MMR-p) patients, the MMR-d patients had higher rate of pelvic and/or para-aortic lymph node metastasis and lymphovascular space invasion $(p=0.011$ and $p=0.015$, respectively). However, other clinico-pathologic variables, including stage, grade, histologic subtype, and depth of invasion, were not associated with MMR status. During the median follow-up period of 18.2 months (1-39.4), there was no difference in progression-free survival between MMR-p and MMR-d patients $(p=0.254)$.

\section{Discussion}

MMR defects were associated with higher rate of lymphovascular space invasion and lymph node metastasis. However, other prognostic factors and survival outcomes were not different between MMR-p and MMR-d patients.

Figure 1. Survival outcomes according to MMR status
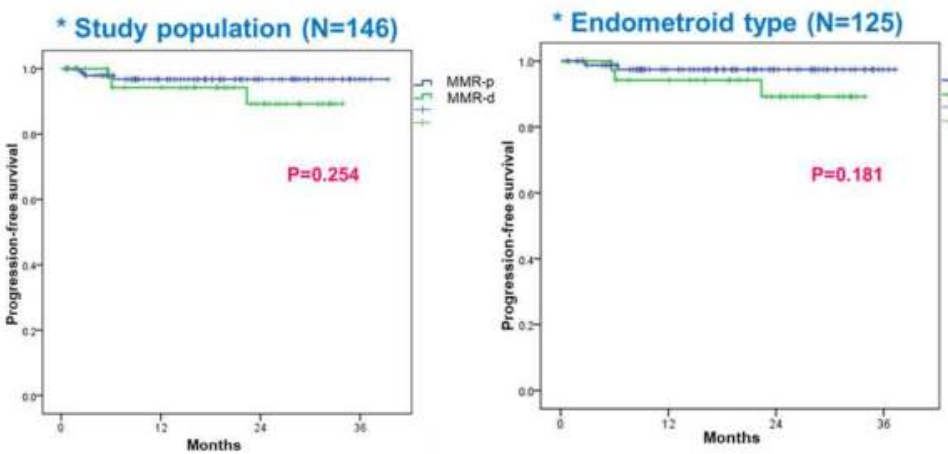

Table 1. Patient characteristics $(\mathrm{N}=146)$

\begin{tabular}{|lc|}
\hline Variables & $n(\%)$ \\
\hline Age at diagnosis, mean (range) & $54.2(26-81)$ \\
\hline BMI, mean (SD), kg/m2 & $25.8+/-4.2(16.9-40.8)$ \\
\hline Menopausal state & \\
Yes & $61(41.8)$ \\
No & $85(58.2)$ \\
\hline DM & $14(9.6)$ \\
\hline Hypertension & $38(26.0)$ \\
\hline FIGO stage & \\
IA & $88(60.3)$ \\
IB & $16(11.0)$ \\
II & $18(12.3)$ \\
IIIA & $4(2.7)$ \\
IIIB & $1(0.7)$ \\
IIIC1 & $4(2.7)$ \\
IIIC2 & $13(8.9)$ \\
IV & $2(1.4)$ \\
\hline MMR-p & $105(71.9)$ \\
MMR-d & $41(28.1)$ \\
\hline MLH1/PMS2 & $28(68.3)$ \\
MSH2/MSH6 & $13(31.7)$ \\
\hline
\end{tabular}

Table 2. Clinicopathologic variables according to MMR status

\begin{tabular}{|c|c|c|c|}
\hline Variables & $\begin{array}{l}\text { MMR-p } \\
(n=105)\end{array}$ & $\begin{array}{l}\text { MMR-d } \\
(n=41)\end{array}$ & p-value \\
\hline Age at diagnosis, mean & 54.2 & 54.2 & 0.997 \\
\hline $\begin{array}{l}\text { Histologic types } \\
\text { Endometrioid } \\
\text { Mucinous } \\
\text { Serous } \\
\text { Clear cell } \\
\text { Others }\end{array}$ & $\begin{array}{l}88(83.8) \\
3(2.9) \\
7(6.7) \\
1(1.0) \\
6(5.7)\end{array}$ & $\begin{array}{c}37(90.2) \\
0(0.0) \\
1(2.4) \\
0(0.0) \\
3(7.3)\end{array}$ & 0.413 \\
\hline $\begin{array}{c}\text { Grade } \\
1 \\
2 \\
3\end{array}$ & $\begin{array}{l}43(41.3) \\
38(36.5) \\
23(22.1)\end{array}$ & $\begin{array}{l}10(24.4) \\
21(51.2) \\
10(24.4)\end{array}$ & 0.140 \\
\hline $\begin{array}{c}\text { Stage } \\
\text { IA } \\
\text { IB } \\
\text { II } \\
\text { IIIA } \\
\text { IIIB } \\
\text { IIIC } \\
\text { IV }\end{array}$ & $\begin{array}{c}67(63.8) \\
12(11.4) \\
13(12.4) \\
3(2.9) \\
1(1.0) \\
8(7.6) \\
1(1.0)\end{array}$ & $\begin{array}{c}21(51.2) \\
4(9.8) \\
5(12.2) \\
1(2.4) \\
0(0.0) \\
9(22.0) \\
1(2.4)\end{array}$ & 0.433 \\
\hline $\begin{array}{l}\text { Depth of invasion } \\
<1 / 2 \\
>1 / 2\end{array}$ & $\begin{array}{l}79(75.2) \\
26(24.8)\end{array}$ & $\begin{array}{l}26(65.0) \\
14(35.0)\end{array}$ & 0.218 \\
\hline $\begin{array}{l}\text { LVSI } \\
\text { negative } \\
\text { positive }\end{array}$ & $\begin{array}{l}61(66.3) \\
31(33.7)\end{array}$ & $\begin{array}{l}17(43.6) \\
22(56.4)\end{array}$ & 0.015 \\
\hline $\begin{array}{l}\text { LN metastasis } \\
\text { negative } \\
\text { positive }\end{array}$ & $\begin{array}{l}96(91.4) \\
9(8.6)\end{array}$ & $\begin{array}{l}31(75.6) \\
10(24.4)\end{array}$ & 0.011 \\
\hline
\end{tabular}

